\title{
PENGEMBANGAN SOAL-SOAL KONTEKSTUAL PADA MATA KULIAH ALJABAR LINEAR BERBASIS MATRIKS LESLIE
}

\author{
Ferryansyah $^{1}$ \\ ${ }^{1}$ Jurusan Pendidikan Matematika, Universitas Borneo Tarakan \\ vrsyah.math@gmail.com
}

\begin{abstract}
Understanding the exact mathematical concepts in students can be obtained through an in-depth process by practicing existing problems in daily life known as contextual learning. Linear Algebra is one of the mathematics courses in the Department of Mathematics Education, Faculty of Teacher Training and Education, University of Borneo Tarakan. But in practicing problem solving students need contextual questions so that the learning abilities obtained by students are more meaningful and students can find out the usefulness of Linear Algebra courses in daily life, especially on matrix material. Eigenvalues and eigenvectors in matrix material are one sub material that can be associated with the Leslie matrix. The Leslie Matrix is a matrix used to predict the number and rate of growth of female population in the City of Tarakan. The development of contextual questions related to the Leslie matrix includes calculating the predicted number of female population growth in one of the kelurahans in the City of Tarakan in the next 5 years and calculating the prediction of the rate of female population growth in one of the kelurahans in the City of Tarakan in the next 5 years.
\end{abstract}

Keywords: Leslie Matrix, Linear Algebra, Contextual Problem Development.

\begin{abstract}
Abstrak
Pemahaman konsep matematika yang tepat pada mahasiswa dapat diperoleh melalui proses yang mendalam dengan melatih permasalahan yang ada dalam kehidupan sehari-hari yang dikenal dengan pembelajaran kontekstual. Aljabar Linear merupakan salah satu mata kuliah matematika pada jurusan Pendidikan Matematika, Fakultas Keguruan dan Ilmu pendidikan, Universitas Borneo Tarakan. Namun dalam melatih pemecahan masalah mahasiswa diperlukan soal-soal kontekstual agar kemampuan pembelajaran yang diperoleh oleh mahasiswa lebih bermakna dan mahasiswa dapat mengetahui kegunaan mata kuliah Aljabar Linear dalam kehidupan sehari-hari khususnya pada materi matriks. Nilai eigen dan vektor eigen pada materi matriks merupakan salah satu sub materi yang dapat dikaitkan dengan matriks Leslie. Matriks Leslie merupakan matriks yang digunakan untuk memprediksi jumlah dan laju pertumbuhan penduduk perempuan di Kota Tarakan. Pengembangan soal kontekstual yang berkaitan dengan matriks Leslie diantaranya meliputi mengitung prediksi jumlah pertambahan penduduk perempuan pada salah satu kelurahan di Kota Tarakan 5 tahun mendatang dan menghitung prediksi laju pertambahan penduduk perempuan pada salah satu kelurahan di Kota Tarakan 5 tahun mendatang.
\end{abstract}

Kata kunci: Matriks Leslie, Aljabar Linear, Pengembangan Soal Kontekstual.

Matematika pada dasarnya diajarkan peserta didik agar dapat digunakan untuk berfikir sistematis dan logis. Akan tetapi sebagian orang beranggapan bahwa matematika hanya digunakan untuk memecahkan masalah dengan cara berhitung atau mengerjakan soal matematika di kelas. Lebih anehnya lagi ada yang menganggap matematika hanya sebatas kumpulan rumus-rumus dan teoremateorema yang digunakan untuk menjawab soal matematika. Hal ini tentu tidak sesuai dengan hakikat matematika. Sebagaimana yang dijelaskan oleh Suherman (2003) bahwa matematika adalah disiplin pemikiran dan prosedur pengolahan logika, baik secara kuantitatif maupun kualitatif.

Pemahaman konsep matematika yang tepat pada peserta didik dapat diperoleh melalui proses yang mendalam dengan melatih permasalahan yang ada dalam kehidupan sehari-hari. Konsep ini yang dikenal dengan pembelajaran kontekstual. Sehingga untuk mendapatakan cara berfikir logis dan 
sistematis perlu latihan pemecahan masalah. Latihan pemacahan masalah berkaitan dengan matematika sudah sering diberikan pada peserta didik mulai dari tingkat sekolah sampai perguruan tinggi. Tentu pada tingkat perguruan tinggi pemecahan masalah yang ada jauh lebih kompleks dibandingkan dengan pemecahan masalah yang ada di tingkat sekolah.

Aljabar Linear merupakan salah satu mata kuliah matematika pada jurusan Pendidikan Matematika, Fakultas Keguruan dan Ilmu pendidikan, Universitas Borneo Tarakan. Peneliti sebagai salah satu pengajar bidang matematika sejauh ini saat memberikan latihan soal kepada mahasiswa hanya berdasarkan soal-soal normatif yang ada di buku. Mahasiswa jarang mengerjakan soal-soal kontekstual apalagi yang berkaitan dengan kehidupan masyarakat yang ada di wilayah Kota Tarakan. Berkaitan dengan permasalahan tersebut diperlukan pengembangan soal-soal kontekstual agar kemampuan pembelajaran yang diperoleh oleh mahasiswa lebih bermakna dan mahasiswa dapat mengetahui kegunaan mata kuliah Aljabar Linear dalam kehidupan sehari-hari khususnya pada sub materi matriks. Oleh karena itu pada studi literatur ini dilakukan pengembangan soal Aljabar Linear berbasis kontekstual yang berkaitan dengan penerapan matriks Leslie dalam memprediksi jumlah dan laju penduduk perempuan di wilayah Kota Tarakan Provinsi Kalimantan Utara.

\section{METODE}

Penelitian ini adalah penelitian studi literatur yang bertujuan mengkaji referensi tentang pengembangan soal Aljabar Linear dari penerapan matriks Leslie dalam memprediksi jumlah dan laju pertumbuhan populasi perempuan di Kota Tarakan. Adapun tahapan penelitian yang sebagai berikut:

1) Menyusun rencana topik yang akan dikaji.

2) Mencari pustaka yang relevan dan memilih materi dari berbagai sumber pustaka yang sesuai.

3) Membuat soal dari penerapan matriks Leslie dalam memprediksi jumlah dan laju pertumbuhan populasi perempuan di Kota Tarakan .

4) Data yang diperoleh dari pengkajian materi dan soal yang dibuat digunakan sebagai acuan untuk membuat pembahasan dan kesimpulan pada penelitian ini

\section{HASIL DAN PEMBAHASAN}

\section{Nilai Eigen Dan Vektor Eigen}

\section{Definisi 1 :}

Jika $A$ adalah matriks $n \times n$, maka vektor tak nol $x$ di dalam $R^{n}$ dinamakan vektor eigen dari $A$. Jika $A x$ adalah kelipatan skalar dari $x$, yaitu :

$$
A x=\lambda x
$$

untuk suatu skalar $\lambda$. Skalar $\lambda$ disebut nilai eigen dari $A$ dan $x$ dikatakan vektor eigen yang bersesuaian dengan $\lambda$. Masalah untuk mencari vektor $x \in R^{n}, x \neq 0$ dan $\lambda$ adalah bilangan real yang memenuhi persamaan : $A x=\lambda x$, disebut masalah nilai eigen (Sutojo dkk, 2010:222). 


\section{Menghitung Nilai Eigen}

Untuk mencari nilai eigen matriks $A$ yang berukuran $n \times n$ maka kita menuliskannya kembali sebagai

$$
A x=\lambda x
$$

Atau

$$
(A-\lambda I) x=0
$$

Dan persamaan diatas akan mempunyai penyelesaian jika

$$
|\mathrm{A}-\lambda \mathrm{I}|=0
$$

Persamaan diatas disebut sebagai persamaan karakteristik $A$. Mencari nilai eigen berarti menghitung determinan tersebut sehingga diperoleh nilai-nilai $\lambda$.

\section{Menghitung Vektor Eigen}

Apabila nilai-nilai eigen diketahui, kemudian nilai-nilai ini dimasukkan ke persamaan :

$$
(A-\lambda I) x=0
$$

Maka akan diperoleh vektor-vektor eigen $x$ yang bersesuaian dengan nilai eigen $\lambda$.

Contoh 1 Tentukan nilai eigen dan vektor eigen untuk matriks berikut :

$$
A=\left[\begin{array}{cc}
-5 & 2 \\
2 & -2
\end{array}\right]
$$

Jawab :

$$
\begin{gathered}
A=\left[\begin{array}{cc}
-5 & 2 \\
2 & -2
\end{array}\right] \\
|A-\lambda I|=0 \\
\left|\left(\begin{array}{cc}
-5 & 2 \\
2 & -2
\end{array}\right)-\lambda\left(\begin{array}{ll}
1 & 0 \\
0 & 1
\end{array}\right)\right|=0 \\
\left|\begin{array}{cc}
-5-\lambda & 2-0 \\
2-0 & -2-\lambda
\end{array}\right|=0 \\
(-5-\lambda)(-2-\lambda)-4=0 \\
2 \lambda+7 \lambda+6 \quad=0 \\
(\lambda+1)(\lambda+6)=0
\end{gathered}
$$

Diperoleh nilai-nilai eigen $\lambda_{1}=-1, \lambda_{2}=-6$. Masukkan nilai-nilai ini kepersamaan

$$
\begin{gathered}
(A-\lambda I) x=0 \\
{\left[\begin{array}{cc}
-5-\lambda & 2 \\
2 & -2-\lambda
\end{array}\right]\left[\begin{array}{l}
x_{1} \\
x_{2}
\end{array}\right]=0}
\end{gathered}
$$

Untuk $\lambda_{1}=-1$, diperoleh persamaan berikut

$$
\begin{gathered}
{\left[\begin{array}{cc}
-4 & 2 \\
2 & -1
\end{array}\right]\left[\begin{array}{l}
x_{1} \\
x_{2}
\end{array}\right]=0} \\
x_{2}=2 x_{1}
\end{gathered}
$$

misalkan $x_{1}=s$, dimana $s$ adalah skalar bilangan real sembarang $\neq 0$, maka

$$
x=\mathrm{s}\left[\begin{array}{l}
1 \\
2
\end{array}\right]
$$


bila diambil nilai $s=1$, maka diperoleh vektor eigen: $x=\left[\begin{array}{l}1 \\ 2\end{array}\right]$ yang berkaitan dengan $\lambda_{1}=-1$. Untuk $\lambda_{2}=-6$, diperoleh persamaan berikut

$$
\begin{gathered}
{\left[\begin{array}{ll}
1 & 2 \\
2 & 4
\end{array}\right]\left[\begin{array}{l}
x_{1} \\
x_{2}
\end{array}\right]=0} \\
x_{1}=-2 x_{1}
\end{gathered}
$$

misalkan $x_{2}=s$, dimana s adalah skalar bilangan real sembarang $\neq 0$, maka

$$
x=s\left[\begin{array}{c}
-2 \\
1
\end{array}\right]
$$

bila diambil nilai $s=1$, maka diperoleh vektor eigen : $x=\left[\begin{array}{c}-2 \\ 1\end{array}\right]$ yang berkaitan dengan $\lambda_{2}=-6$.

\section{Membuat Model Matriks Leslie}

Membuat model matriks leslie untuk menghitung prediksi jumlah populasi perempuan yang digunakan adalah tabel penentuan kelas umur (Tabel 2.1). Tabel penentuan kelas umur ini akan dibuat dalam bentuk tabel, yaitu tabel populasi perempuan di Kelurahan Selumit Pantai yang terdiri dari 5 kolom yaitu Kelas Umur $(i)$, Interval Umur, Populasi Awal $\left(x_{i}^{0}\right)$, Kelahiran $\left(A_{i}\right)$ dan Kematian $\left(B_{i}\right)$. Berikut adalah tabel populasi perempuan, dengan penentuan kelas umur dimana $L$ adalah umur maksimum dari populasi perempuan, dan $n$ adalah banyaknya kelas umur.

Tabel 1. Penentuan Kelas Umur

\begin{tabular}{ccccc}
\hline $\begin{array}{c}\text { Kelas } \\
\text { umur }(i)\end{array}$ & Interval umur & $\begin{array}{c}\text { Populasi awal } \\
\left(x_{i}^{0}\right)\end{array}$ & Kelahiran $\left(A_{i}\right)$ & Kematian $\left(B_{i}\right)$ \\
\hline 1 & {$\left[0, \frac{L}{n}\right]$} & $x_{1}^{(0)}$ & $A_{1}$ & $B_{1}$ \\
\hline 2 & {$\left[\frac{L}{n}, 2 \frac{L}{n}\right]$} & $x_{2}^{(0)}$ & $A_{2}$ & $B_{2}$ \\
\hline$\vdots$ & $\vdots$ & $\vdots$ & $\vdots$ & $\vdots$ \\
\hline$n$ & {$\left[(n-1)^{L} / n, L\right]$} & $x_{n}^{(0)}$ & $A_{n}$ & $B_{n}$ \\
\hline
\end{tabular}

(Sumber : Modifikasi dari Anton Rorres, 2005)

Membentuk model matriks leslie untuk memprediksi jumlah pertumbuhan populasi perempuan

a. Mencari nilai tingkat kesuburan $\left(a_{i}\right)$ yaitu rata-rata jumlah anak perempuan yang lahir dari tiap perempuan ketika si ibu berada dalam kelas umur ke- $i$.

$$
a_{i}=\frac{A_{i}}{x_{i}^{0}}
$$

Dimana :

$a_{i}=$ Tingkat kesuburan

$A_{i}=$ banyaknya kelahiran pada kelas umur ke- $i$

$x_{i}^{o}=$ populasi awal

b. Mencari nilai tingkat ketahanan hidup $\left(b_{i}\right)$ yaitu perbandingan perempuan pada kelas umur ke- $i$ yang diharapkan dapat bertahan dan mencapai kelas umur ke- $(i+1)$.

$$
b_{i}=\left(1-c_{i}^{k-1}\right)
$$

Dimana: 
$c_{i}^{k-1}=$ rata-rata jumlah kematian dari tiap kelas umur

$B_{i}=$ banyaknya kematian pada kelas umur ke- $i$

$b_{i}=$ tingkat ketahanan hidup

c. Menentukan model Matriks Leslie

$$
L=\left[\begin{array}{cccccc}
a_{1} & a_{2} & a_{3} & \cdots & a_{n-1} & a_{n} \\
b_{1} & 0 & 0 & \cdots & 0 & 0 \\
0 & b_{2} & 0 & \cdots & 0 & 0 \\
\vdots & \vdots & \vdots & \ddots & \vdots & \vdots \\
0 & 0 & 0 & \cdots & b_{n-1} & 0
\end{array}\right]
$$

\section{Penyelesaian Model Matriks Leslie}

a. Menghitung Prediksi Jumlah Pertumbuhan Penduduk

Model matriks Leslie yang telah dibuat sebelumnya dikalikan dengan populasi awal, diselesaikan menggunakan $x^{(k)}=L x^{(k-1)}$. Peneliti menggunakan operasi perkalian matriks yang berbantu aplikasi Matrix Calculator untuk mendapatkan hasil jumlah populasi perempuan pada tiap kelas umur. Kemudian jumlah populasi perempuan pada tiap kelas umur di total, sehingga diperolah jumlah populasi perempuan pada tahun 2023.

b. Menghitung Prediksi Laju Pertumbuhan Penduduk

Selanjutnya untuk menghitung prediksi laju pertumbuhan pennduduk, model matriks leslie yang telah dbuat sebelumnya, diselesaikan dengan persamaan karakteristik yaitu $p(\lambda)=|\lambda I-L|$ dengan mencari nilai eigen berarti menghitung determinan persamaan tersebut, sehingga diperoleh persamaan karakteristiknya. Peneliti menggunakan operasi perkalian dan pengurangan matriks. Setelah mendapatkan persamaan karakteristiknya kemudian diselesaikan dengan berbantu software MATLAB untuk mendapatkan nilai-nilai eigennya. Dari nilai-nilai eigen dicari nilai eigen positif $\lambda_{1}$.

Tiga kasus yang muncul berkaitan dengan nilai dari nilai eigen positif $\lambda_{1}$, yaitu:

1). Suatu populasi akhirnya meningkat jika $\lambda_{1}>1$

2). Suatu populasi akhirnya berkurang jika $\lambda_{1}<1$

3). Suatu populasi cenderung stabil jika $\lambda_{1}=1$

\section{Prediksi Jumlah dan Laju Pertumbuhan Penduduk Perempuan di Kota Tarakan}

Penelitian Paramitha (2019) diperoleh data banyaknya perempuan di Selumit Pantai Kota Tarakan

Tabel 2. Banyak Perempuan Setiap RT

\begin{tabular}{ccc}
\hline No & Rukun Tetangga & Banyak Perempuan \\
\hline 1 & RT 01 & 383 \\
\hline 2 & RT 02 & 239 \\
\hline 3 & RT 03 & 301 \\
\hline 4 & RT 04 & 220 \\
\hline 5 & RT 05 & 577 \\
\hline 6 & RT 06 & 55 \\
\hline 7 & RT 07 & 222 \\
\hline 8 & RT 08 & 251 \\
\hline
\end{tabular}




\begin{tabular}{lll}
\hline 9 & RT 09 & 339 \\
\hline 10 & RT 10 & 255 \\
\hline 11 & RT 11 & 232 \\
\hline 12 & RT 12 & 317 \\
\hline 13 & RT 13 & 248 \\
\hline 14 & RT 14 & 317 \\
\hline 15 & RT 15 & 677 \\
\hline 16 & RT 16 & 419 \\
\hline 17 & RT 17 & 309 \\
\hline 18 & RT 18 & 572 \\
\hline 19 & RT 19 & 521 \\
\hline 20 & RT 20 & 282 \\
\hline 21 & RT 21 & 217 \\
\hline 22 & RT 22 & 301 \\
\hline 23 & RT 23 & 574 \\
\hline 24 & RT 24 & 173 \\
\hline 25 & RT 25 & 118 \\
\hline 26 & RT 26 & 412 \\
\hline 27 & RT 27 & 376 \\
\hline 28 & RT 28 & 374 \\
\hline 29 & RT 29 & 240 \\
\hline
\end{tabular}

(Sumber : Paramitha, 2019)

Data yang diperoleh kemudian oleh masing-masing kelompok dibagi menjadi kelas-kelas umur dalam interval waktu yang sama. Kemudian disajikan data populasi perempuan di Kelurahan Selumit Pantai pada tabel berikut

Tabel 3. Data Populasi Perempuan di Kelurahan Selumit Pantai pada tahun 2013-2018

\begin{tabular}{|c|c|c|c|c|}
\hline Kelas Umur (i) & Interval Umur & Populasi Awal $\left(\boldsymbol{x}_{\boldsymbol{i}}^{\mathbf{0}}\right)$ & Kelahiran $\left(\boldsymbol{A}_{\boldsymbol{i}}\right)$ & Kematian $\left(\boldsymbol{B}_{\boldsymbol{i}}\right)$ \\
\hline 1 & $0-4$ & 191 & 0 & 0 \\
\hline 2 & $5-9$ & 274 & 0 & 0 \\
\hline 3 & $10-14$ & 527 & 0 & 0 \\
\hline 4 & $15-19$ & 843 & 271 & 2 \\
\hline 5 & $20-24$ & 1372 & 601 & 0 \\
\hline 6 & $25-29$ & 1501 & 520 & 1 \\
\hline 7 & $30-34$ & 1420 & 215 & 0 \\
\hline 8 & $35-39$ & 927 & 187 & 0 \\
\hline 9 & $40-44$ & 796 & 56 & 0 \\
\hline 10 & $45-49$ & 729 & 0 & 1 \\
\hline 11 & $50-54$ & 403 & 0 & 0 \\
\hline 12 & $55-59$ & 249 & 0 & 0 \\
\hline 13 & $60-64$ & 93 & 0 & 0 \\
\hline 14 & $65-69$ & 81 & 0 & 2 \\
\hline 15 & $70-74$ & 46 & 0 & 0 \\
\hline 16 & $75-79$ & 41 & 0 & 0 \\
\hline 17 & $80-84$ & 8 & 0 & 2 \\
\hline 18 & $85-89$ & 11 & 0 & 0 \\
\hline
\end{tabular}




\begin{tabular}{ccccc}
\hline 19 & $90-94$ & 2 & 0 & 0 \\
\hline 20 & $95-99$ & 6 & 0 & 3 \\
\hline Total & & $\mathbf{9 5 2 0}$ & $\mathbf{1 8 5 0}$ & $\mathbf{1 1}$
\end{tabular}

(Sumber : Paramitha, 2019)

Data mengenai populasi perempuan di Kelurahan Selumit Pantai yang digunakan untuk menghitung jumlah dan laju pertumbuhan populasi di formulasikan ke dalam bentuk matriks leslie. Sehingga dapat diketahui prediksi jumlah dan laju pertumbuhan di Kelurahan selumit Pantai pada 5 tahun mendatang. Dengan berbantu aplikasi Matrix Calculator untuk menghitung jumlah populasi perempuan dan software MATLAB untuk menghitung laju pertumbuhan populasi perempuan.

Tabel 4. Tingkat Kesuburan dan Ketahanan hidup perempuan di Kelurahan Selumit Pantai tahun 2013-2018

\begin{tabular}{cccc}
\hline $\begin{array}{c}\text { Kelas } \\
\text { Umur } \\
(\boldsymbol{i})\end{array}$ & $\begin{array}{c}\text { Tingkat } \\
\text { Kesuburan } \\
\left(\boldsymbol{a}_{\boldsymbol{i}}\right)\end{array}$ & $\begin{array}{c}\text { Rata-rata } \\
\text { Kematian } \\
\left(\boldsymbol{c}_{\boldsymbol{i}}^{\boldsymbol{k}-\mathbf{1}}\right)\end{array}$ & $\begin{array}{c}\text { Tingkat } \\
\text { Ketahanan } \\
\left(\boldsymbol{b}_{\boldsymbol{i}}\right)\end{array}$ \\
\hline 1 & 0 & 0 & 1 \\
2 & 0 & 0 & 1 \\
3 & 0 & 0 & 1 \\
4 & 0,321 & 0,0023 & 0,997 \\
5 & 0,438 & 0 & 1 \\
6 & 0,346 & 0,0006 & 0,999 \\
7 & 0,151 & 0 & 1 \\
8 & 0,201 & 0 & 1 \\
9 & 0,07 & 0 & 1 \\
10 & 0 & 0,0013 & 0,998 \\
11 & 0 & 0 & 1 \\
12 & 0 & 0 & 1 \\
13 & 0 & 0 & 1 \\
14 & 0 & 0,0246 & 0,975 \\
15 & 0 & 0 & 1 \\
16 & 0 & 0 & 1 \\
17 & 0 & 0 & 1 \\
18 & 0 & 0 & 1 \\
19 & 0 & 0 & 1 \\
20 & 0 & 0,5 & 0,5 \\
\hline$:$ Paran & 0 & &
\end{tabular}

(Sumber : Paramitha, 2019) 


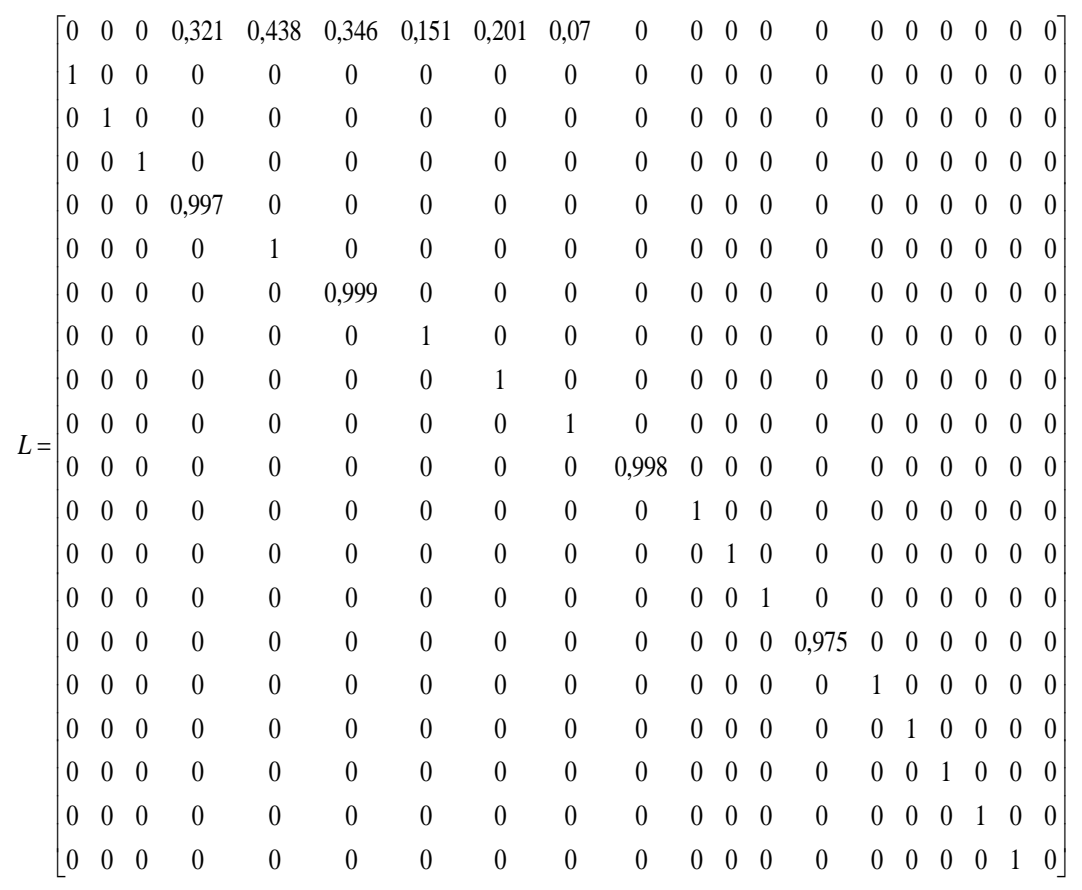

Dari hasil analisis Matriks Leslie mempersyaratkan bahwa durasi antara dua waktu pengamatan berurutan sama dengan interval umur, yaitu 5 tahun. Jika distribusi umur awal permulaan perempuan pada tahun 2013, dan distribusi umur perempuan pada tahun 2018 (pengamatan pada waktu $\left.t_{1}\right)$, maka dapat diproyeksikan distribusi umur perempuan pada tahun $2023\left(t_{2}\right)$, dan seterusnya. Sehingga dari persamaan di atas diperoleh model pertumbuhan populasi perempuan di Kelurahan Selumit Pantai yaitu :

$x^{5}=\left[\begin{array}{cccccccccccccccccccc}0 & 0 & 0 & 0,321 & 0,438 & 0,346 & 0,151 & 0,201 & 0,07 & 0 & 0 & 0 & 0 & 0 & 0 & 0 & 0 & 0 & 0 & 0 \\ 1 & 0 & 0 & 0 & 0 & 0 & 0 & 0 & 0 & 0 & 0 & 0 & 0 & 0 & 0 & 0 & 0 & 0 & 0 & 0 \\ 0 & 1 & 0 & 0 & 0 & 0 & 0 & 0 & 0 & 0 & 0 & 0 & 0 & 0 & 0 & 0 & 0 & 0 & 0 & 0 \\ 0 & 0 & 1 & 0 & 0 & 0 & 0 & 0 & 0 & 0 & 0 & 0 & 0 & 0 & 0 & 0 & 0 & 0 & 0 & 0 \\ 0 & 0 & 0 & 0,997 & 0 & 0 & 0 & 0 & 0 & 0 & 0 & 0 & 0 & 0 & 0 & 0 & 0 & 0 & 0 & 0 \\ 0 & 0 & 0 & 0 & 1 & 0 & 0 & 0 & 0 & 0 & 0 & 0 & 0 & 0 & 0 & 0 & 0 & 0 & 0 & 0 \\ 0 & 0 & 0 & 0 & 0 & 0,999 & 0 & 0 & 0 & 0 & 0 & 0 & 0 & 0 & 0 & 0 & 0 & 0 & 0 & 0 \\ 0 & 0 & 0 & 0 & 0 & 0 & 1 & 0 & 0 & 0 & 0 & 0 & 0 & 0 & 0 & 0 & 0 & 0 & 0 & 0 \\ 0 & 0 & 0 & 0 & 0 & 0 & 0 & 1 & 0 & 0 & 0 & 0 & 0 & 0 & 0 & 0 & 0 & 0 & 0 & 0 \\ 0 & 0 & 0 & 0 & 0 & 0 & 0 & 0 & 1 & 0 & 0 & 0 & 0 & 0 & 0 & 0 & 0 & 0 & 0 & 0 \\ 0 & 0 & 0 & 0 & 0 & 0 & 0 & 0 & 0 & 0 & 1 & 0 & 0 & 0 & 0 & 0 & 0 & 0 & 0 & 0 \\ 0 & 0 & 0 & 0 & 0 & 0 & 0 & 0 & 0 & 0 & 0 & 1 & 0 & 0 & 0 & 0 & 0 & 0 & 0 & 0 \\ 0 & 0 & 0 & 0 & 0 & 0 & 0 & 0 & 0 & 0 & 0 & 0 & 1 & 0 & 0 & 0 & 0 & 0 & 0 & 0 \\ 0 & 0 & 0 & 0 & 0 & 0 & 0 & 0 & 0 & 0 & 0 & 0 & 0 & 0,975 & 0 & 0 & 0 & 0 & 0 & 0 \\ 0 & 0 & 0 & 0 & 0 & 0 & 0 & 0 & 0 & 0 & 0 & 0 & 0 & 0 & 1 & 0 & 0 & 0 & 0 & 0 \\ 0 & 0 & 0 & 0 & 0 & 0 & 0 & 0 & 0 & 0 & 0 & 0 & 0 & 0 & 0 & 1 & 0 & 0 & 0 & 0 \\ 0 & 0 & 0 & 0 & 0 & 0 & 0 & 0 & 0 & 0 & 0 & 0 & 0 & 0 & 0 & 0 & 1 & 0 & 0 & 0 \\ 0 & 0 & 0 & 0 & 0 & 0 & 0 & 0 & 0 & 0 & 0 & 0 & 0 & 0 & 0 & 0 & 0 & 1 & 0 & 0 \\ 0 & 0 & 0 & 0 & 0 & 0 & 0 & 0 & 0 & 0 & 0 & 0 & 0 & 0 & 0 & 0 & 0 & 0 & 1 & 0\end{array}\right]^{5}\left[\begin{array}{c}191 \\ 274 \\ 527 \\ 843 \\ 1372 \\ 1501 \\ 1420 \\ 927 \\ 796 \\ 729 \\ 403 \\ 249 \\ 93 \\ 81 \\ 46 \\ 41 \\ 8 \\ 11 \\ 190,4 \\ 1216,6 \\ 1588,7 \\ 1841,8 \\ 272,9 \\ 524,8 \\ 839,6 \\ 1370,6 \\ 1496,5 \\ 1417,1 \\ 925,1 \\ 6 \\ 794,4 \\ 709,3 \\ 392,9 \\ 242,7 \\ 90,6 \\ 78,9 \\ 76\end{array}\right]$

Sehingga dengan pembulatan nilai, maka prediksi populasi pada tiap-tiap kelas dijumlahkan sebagai berikut :

$x^{5}=1115+870+1217+1589+1842+190+273+525+840+1371+149$ 


$$
+1417+925+794+709+393+243+91+79+46=16.025
$$

Sehingga pada tahun 2023 prediksi jumlah populasi perempuan di Kelurahan Selumit Pantai adalah 16.025 jiwa perempuan dibandingkan dengan popuasi perempuan pada tahun 2018 yaitu hanya 11.370 jiwa.

Dengan menggunakan nilai eigen dari Matriks Leslie dapat ditentukan prediksi laju pertumbuhan populasi penduduk perempuan di Kelurahan Selumit Pantai. Maka akan ditentukan nilai eigen positif dari $\lambda_{1}$. Dalam kasus ini $\lambda_{1}$ akan menentukan suatu populasi akan cenderung meningkat, cenderung menurun, atau suatu populasi akan cenderung stabil. Adapun rumus yang digunakan untuk mencari nilai eigen dari Matriks Leslie yaitu :

$$
p(\lambda)=|L-\lambda I|
$$

Dengan menggunakan aplikasi MATLAB maka diperoleh nilai eigen dari Matriks Leslie yaitu :

$$
\begin{aligned}
& p(\lambda)=\left[\begin{array}{cccccccccccccccccccc}
0 & 0 & 0 & 0,321 & 0,438 & 0,346 & 0,151 & 0,201 & 0,07 & 0 & 0 & 0 & 0 & 0 & 0 & 0 & 0 & 0 & 0 & 0 \\
1 & 0 & 0 & 0 & 0 & 0 & 0 & 0 & 0 & 0 & 0 & 0 & 0 & 0 & 0 & 0 & 0 & 0 & 0 & 0 \\
0 & 1 & 0 & 0 & 0 & 0 & 0 & 0 & 0 & 0 & 0 & 0 & 0 & 0 & 0 & 0 & 0 & 0 & 0 & 0 \\
0 & 0 & 1 & 0 & 0 & 0 & 0 & 0 & 0 & 0 & 0 & 0 & 0 & 0 & 0 & 0 & 0 & 0 & 0 & 0 \\
0 & 0 & 0 & 0,997 & 0 & 0 & 0 & 0 & 0 & 0 & 0 & 0 & 0 & 0 & 0 & 0 & 0 & 0 & 0 & 0 \\
0 & 0 & 0 & 0 & 1 & 0 & 0 & 0 & 0 & 0 & 0 & 0 & 0 & 0 & 0 & 0 & 0 & 0 & 0 & 0 \\
0 & 0 & 0 & 0 & 0 & 0,999 & 0 & 0 & 0 & 0 & 0 & 0 & 0 & 0 & 0 & 0 & 0 & 0 & 0 & 0 \\
0 & 0 & 0 & 0 & 0 & 0 & 1 & 0 & 0 & 0 & 0 & 0 & 0 & 0 & 0 & 0 & 0 & 0 & 0 & 0 \\
0 & 0 & 0 & 0 & 0 & 0 & 0 & 1 & 0 & 0 & 0 & 0 & 0 & 0 & 0 & 0 & 0 & 0 & 0 & 0 \\
0 & 0 & 0 & 0 & 0 & 0 & 0 & 0 & 1 & 0 & 0 & 0 & 0 & 0 & 0 & 0 & 0 & 0 & 0 & 0 \\
0 & 0 & 0 & 0 & 0 & 0 & 0 & 0 & 0 & 0,998 & 0 & 0 & 0 & 0 & 0 & 0 & 0 & 0 & 0 & 0 \\
0 & 0 & 0 & 0 & 0 & 0 & 0 & 0 & 0 & 0 & 1 & 0 & 0 & 0 & 0 & 0 & 0 & 0 & 0 & 0 \\
0 & 0 & 0 & 0 & 0 & 0 & 0 & 0 & 0 & 0 & 0 & 1 & 0 & 0 & 0 & 0 & 0 & 0 & 0 & 0 \\
0 & 0 & 0 & 0 & 0 & 0 & 0 & 0 & 0 & 0 & 0 & 0 & 1 & 0 & 0 & 0 & 0 & 0 & 0 & 0 \\
0 & 0 & 0 & 0 & 0 & 0 & 0 & 0 & 0 & 0 & 0 & 0 & 0 & 0,975 & 0 & 0 & 0 & 0 & 0 & 0 \\
0 & 0 & 0 & 0 & 0 & 0 & 0 & 0 & 0 & 0 & 0 & 0 & 0 & 0 & 1 & 0 & 0 & 0 & 0 & 0 \\
0 & 0 & 0 & 0 & 0 & 0 & 0 & 0 & 0 & 0 & 0 & 0 & 0 & 0 & 0 & 1 & 0 & 0 & 0 & 0 \\
0 & 0 & 0 & 0 & 0 & 0 & 0 & 0 & 0 & 0 & 0 & 0 & 0 & 0 & 0 & 0 & 1 & 0 & 0 & 0 \\
0 & 0 & 0 & 0 & 0 & 0 & 0 & 0 & 0 & 0 & 0 & 0 & 0 & 0 & 0 & 0 & 0 & 1 & 0 & 0 \\
0 & 0 & 0 & 0 & 0 & 0 & 0 & 0 & 0 & 0 & 0 & 0 & 0 & 0 & 0 & 0 & 0 & 0 & 1 & 0
\end{array}\right] \\
& {\left[\begin{array}{llllllllllllllllllll}
\lambda & 0 & 0 & 0 & 0 & 0 & 0 & 0 & 0 & 0 & 0 & 0 & 0 & 0 & 0 & 0 & 0 & 0 & 0 & 0 \\
0 & \lambda & 0 & 0 & 0 & 0 & 0 & 0 & 0 & 0 & 0 & 0 & 0 & 0 & 0 & 0 & 0 & 0 & 0 & 0 \\
0 & 0 & \lambda & 0 & 0 & 0 & 0 & 0 & 0 & 0 & 0 & 0 & 0 & 0 & 0 & 0 & 0 & 0 & 0 & 0 \\
0 & 0 & 0 & \lambda & 0 & 0 & 0 & 0 & 0 & 0 & 0 & 0 & 0 & 0 & 0 & 0 & 0 & 0 & 0 & 0 \\
0 & 0 & 0 & 0 & \lambda & 0 & 0 & 0 & 0 & 0 & 0 & 0 & 0 & 0 & 0 & 0 & 0 & 0 & 0 & 0 \\
0 & 0 & 0 & 0 & 0 & \lambda & 0 & 0 & 0 & 0 & 0 & 0 & 0 & 0 & 0 & 0 & 0 & 0 & 0 & 0 \\
0 & 0 & 0 & 0 & 0 & 0 & \lambda & 0 & 0 & 0 & 0 & 0 & 0 & 0 & 0 & 0 & 0 & 0 & 0 & 0 \\
0 & 0 & 0 & 0 & 0 & 0 & 0 & \lambda & 0 & 0 & 0 & 0 & 0 & 0 & 0 & 0 & 0 & 0 & 0 & 0 \\
0 & 0 & 0 & 0 & 0 & 0 & 0 & 0 & \lambda & 0 & 0 & 0 & 0 & 0 & 0 & 0 & 0 & 0 & 0 & 0 \\
0 & 0 & 0 & 0 & 0 & 0 & 0 & 0 & 0 & \lambda & 0 & 0 & 0 & 0 & 0 & 0 & 0 & 0 & 0 & 0 \\
0 & 0 & 0 & 0 & 0 & 0 & 0 & 0 & 0 & 0 & \lambda & 0 & 0 & 0 & 0 & 0 & 0 & 0 & 0 & 0 \\
0 & 0 & 0 & 0 & 0 & 0 & 0 & 0 & 0 & 0 & 0 & \lambda & 0 & 0 & 0 & 0 & 0 & 0 & 0 & 0 \\
0 & 0 & 0 & 0 & 0 & 0 & 0 & 0 & 0 & 0 & 0 & 0 & \lambda & 0 & 0 & 0 & 0 & 0 & 0 & 0 \\
0 & 0 & 0 & 0 & 0 & 0 & 0 & 0 & 0 & 0 & 0 & 0 & 0 & \lambda & 0 & 0 & 0 & 0 & 0 & 0 \\
0 & 0 & 0 & 0 & 0 & 0 & 0 & 0 & 0 & 0 & 0 & 0 & 0 & 0 & \lambda & 0 & 0 & 0 & 0 & 0 \\
0 & 0 & 0 & 0 & 0 & 0 & 0 & 0 & 0 & 0 & 0 & 0 & 0 & 0 & 0 & \lambda & 0 & 0 & 0 & 0 \\
0 & 0 & 0 & 0 & 0 & 0 & 0 & 0 & 0 & 0 & 0 & 0 & 0 & 0 & 0 & 0 & \lambda & 0 & 0 & 0 \\
0 & 0 & 0 & 0 & 0 & 0 & 0 & 0 & 0 & 0 & 0 & 0 & 0 & 0 & 0 & 0 & 0 & \lambda & 0 & 0 \\
0 & 0 & 0 & 0 & 0 & 0 & 0 & 0 & 0 & 0 & 0 & 0 & 0 & 0 & 0 & 0 & 0 & 0 & \lambda & 0 \\
0 & 0 & 0 & 0 & 0 & 0 & 0 & 0 & 0 & 0 & 0 & 0 & 0 & 0 & 0 & 0 & 0 & 0 & 0 & \lambda
\end{array}\right]}
\end{aligned}
$$




$p(\lambda)=\left[\begin{array}{cccccccccccccccccccc}-\lambda & 0 & 0 & 0,321 & 0,438 & 0,346 & 0,151 & 0,201 & 0,07 & 0 & 0 & 0 & 0 & 0 & 0 & 0 & 0 & 0 & 0 & 0 \\ 1 & -\lambda & 0 & 0 & 0 & 0 & 0 & 0 & 0 & 0 & 0 & 0 & 0 & 0 & 0 & 0 & 0 & 0 & 0 & 0 \\ 0 & 1 & -\lambda & 0 & 0 & 0 & 0 & 0 & 0 & 0 & 0 & 0 & 0 & 0 & 0 & 0 & 0 & 0 & 0 & 0 \\ 0 & 0 & 1 & -\lambda & 0 & 0 & 0 & 0 & 0 & 0 & 0 & 0 & 0 & 0 & 0 & 0 & 0 & 0 & 0 & 0 \\ 0 & 0 & 0 & 0,997 & -\lambda & 0 & 0 & 0 & 0 & 0 & 0 & 0 & 0 & 0 & 0 & 0 & 0 & 0 & 0 & 0 \\ 0 & 0 & 0 & 0 & 1 & -\lambda & 0 & 0 & 0 & 0 & 0 & 0 & 0 & 0 & 0 & 0 & 0 & 0 & 0 & 0 \\ 0 & 0 & 0 & 0 & 0 & 0,999 & -\lambda & 0 & 0 & 0 & 0 & 0 & 0 & 0 & 0 & 0 & 0 & 0 & 0 & 0 \\ 0 & 0 & 0 & 0 & 0 & 0 & 1 & -\lambda & 0 & 0 & 0 & 0 & 0 & 0 & 0 & 0 & 0 & 0 & 0 & 0 \\ 0 & 0 & 0 & 0 & 0 & 0 & 0 & 1 & -\lambda & 0 & 0 & 0 & 0 & 0 & 0 & 0 & 0 & 0 & 0 & 0 \\ 0 & 0 & 0 & 0 & 0 & 0 & 0 & 0 & 1 & -\lambda & 0 & 0 & 0 & 0 & 0 & 0 & 0 & 0 & 0 & 0 \\ 0 & 0 & 0 & 0 & 0 & 0 & 0 & 0 & 0 & 0,998 & -\lambda & 0 & 0 & 0 & 0 & 0 & 0 & 0 & 0 & 0 \\ 0 & 0 & 0 & 0 & 0 & 0 & 0 & 0 & 0 & 0 & 1 & -\lambda & 0 & 0 & 0 & 0 & 0 & 0 & 0 & 0 \\ 0 & 0 & 0 & 0 & 0 & 0 & 0 & 0 & 0 & 0 & 0 & 1 & -\lambda & 0 & 0 & 0 & 0 & 0 & 0 & 0 \\ 0 & 0 & 0 & 0 & 0 & 0 & 0 & 0 & 0 & 0 & 0 & 0 & 1 & -\lambda & 0 & 0 & 0 & 0 & 0 & 0 \\ 0 & 0 & 0 & 0 & 0 & 0 & 0 & 0 & 0 & 0 & 0 & 0 & 0 & 0,975 & -\lambda & 0 & 0 & 0 & 0 & 0 \\ 0 & 0 & 0 & 0 & 0 & 0 & 0 & 0 & 0 & 0 & 0 & 0 & 0 & 0 & 1 & -\lambda & 0 & 0 & 0 & 0 \\ 0 & 0 & 0 & 0 & 0 & 0 & 0 & 0 & 0 & 0 & 0 & 0 & 0 & 0 & 0 & 1 & -\lambda & 0 & 0 & 0 \\ 0 & 0 & 0 & 0 & 0 & 0 & 0 & 0 & 0 & 0 & 0 & 0 & 0 & 0 & 0 & 0 & 1 & -\lambda & 0 & 0 \\ 0 & 0 & 0 & 0 & 0 & 0 & 0 & 0 & 0 & 0 & 0 & 0 & 0 & 0 & 0 & 0 & 0 & 1 & -\lambda & 0 \\ 0 & 0 & 0 & 0 & 0 & 0 & 0 & 0 & 0 & 0 & 0 & 0 & 0 & 0 & 0 & 0 & 0 & 0 & 1 & -\lambda\end{array}\right]$

Sehingga diperoleh persamaan karakteristiknya yaitu :

$$
\begin{aligned}
p(\lambda)= & \lambda^{20}-0,321 \lambda^{16}-0,436686 \lambda^{15}-0,344962 \lambda^{14}-0,150396453 \lambda^{13} \\
& -0,200196603 \lambda^{12}-0,06972021 \lambda^{\wedge} 11
\end{aligned}
$$

Dari persamaan karakteristik diatas diperoleh nilai eigen sebagai berikut : $\lambda_{1}=1.0764, \quad \lambda_{2}=0.3916+0.6628 i, \quad \lambda_{3}=0.3916-0.6628 i, \quad \lambda_{4}=0.1489+0.7838 i, \quad \lambda_{5}=$ $0.1489-0.7838 i, \quad \lambda_{6}=-0.5008+0.5640 i, \quad \lambda_{7}=-0.5008-0.5640 i, \quad \lambda_{8}=0.7571, \quad \lambda_{9}=$ 0.3987, $\lambda_{10}=0, \lambda_{11}=0, \lambda_{12}=0, \lambda_{13}=0, \lambda_{14}=0, \lambda_{15}=0, \lambda_{16}=0, \lambda_{17}=0, \lambda_{18}=0, \lambda_{19}=0$, $\lambda_{20}=0$

Dan nilai eigen dominan adalah $\lambda_{1}=1,0764$. Sedemikian sehinggga dengan nilai eigen dominan ini dapat menunjukkan pertumbuhan populasi perempuan di Kelurahan Selumit Pantai. Karena nilai eigen dominan lebih besar dari satu, maka nilai ini menunjukkan bahwa laju pertumbuhan penduduk di Kelurahan Selumit Pantai cenderung meningkat.

\section{Soal-soal Kontekstul Mata Kuliah Aljabar Linear}

Pengembangan soal kontekstual yang dapat dibuat berkaitan dengan penggunaan matriks Leslie dalam memprediksi jumlah dan laju pertumbuhan perempuan di Kota Tarakan sebagai berikut :

Kota Tarakan adalah sebuah kota di Provinsi Kalimantan Utara, Indonesia dan juga merupakan kota terbesar di Kalimantan Utara, sekaligus kota terkaya ke-17 di Indonesia. Sesuai dengan data Badan Kependudukan Catatan Sipil dan Keluarga Berencana, Kota Tarakan berpenduduk sebanyak 253.026 jiwa pada tahun 2019 dengan luas wilayah $250,80 \mathrm{~km}^{2}$. Perempuan dengan tingkat kesuburan dan ketahanan hidup tinggi merupakan penyumbang padatnya jumlah penduduk disuatu wilayah. Oleh karena itu, Coba Kalian lakukan prediksi terhadap jumlah dan laju pertambahan penduduk perempuan pada salah satu kelurahan di Kota Tarakan tersebut 5 tahun mendatang dengan terlebih dahulu mengidentifikasi jumlah penduduk perempuan salah satu kelurahan di Kota Tarakan pada tahun 2019. Hasil identifikasi tersebut kemudian sajikan ke dalam tabel penentuan kelas umur 
agar dapat dihitung tingkat kesuburan dan tingkat ketahanan hidup penduduk perempuan tersebut, serta dapat dibuat model matriks Leslie dari data penduduk perempuan tersebut.

\section{KESIMPULAN}

Matrik Leslie adalah matriks yang dapat digunakan untuk menghitung prediksi jumlah dan laju pertumbuhan penduduk perempuan pada suatu daerah. Penelitian terhadap penerapan matriks Leslie telah dilakukan pada Kelurahan Selumit Pantai di Kota Tarakan Provinsi Kalimantan Utara. Adapun hasil penelitian tersebut diperoleh pada tahun 2023 prediksi jumlah populasi perempuan di Kelurahan Selumit Pantai adalah 16.025 jiwa perempuan dibandingkan dengan popuasi perempuan pada tahun 2018 yaitu hanya 11.370 jiwa dan laju pertumbuhan penduduk di Kelurahan Selumit Pantai cenderung meningkat. Berdasarkan hasil penelitian tersebut dapat dikembangkan soal pada mata kuliah Aljabar Linear berkaitan dengan penggunaan nilai eigen dan vektor eigen dalam kehidupan masyarakat di Kota Tarakan. Pengembangan soal tersebut diantaranya meliputi menghitung prediksi jumlah pertambahan penduduk perempuan pada salah satu kelurahan di Kota Tarakan 5 tahun mendatang dan menghitung prediksi laju pertambahan penduduk perempuan pada salah satu kelurahan di Kota Tarakan 5 tahun mendatang

\section{DAFTAR PUSTAKA}

Anton, Howard dan Chris Rorres. 2005. Aljabar Linear Elementer (Versi Aplikasi). Erlangga, Jakarta. Paramitha, Ferryansyah, \& Hermansyah. (2019). Prediksi Jumlah Dan Laju Pertumbuhan Perempuan Dengan Menggunakan Matriks Leslie Pada Tahun 2023 (Studi Kasus: Kelurahan Selumit Pantai Kota Tarakan, Kalimantan Utara). Univeristas Borneo Tarakan. Skripsi Tidak diterbitkan Suherman, Erman. (2003). Strategi Pembelajaran Matematika Kontemporer. Bandung: JICA Universitas Pendidikan Indonesia.

Sutojo, dkk. (2009). Teori dan Aplikasi Aljabar Linier \& Matriks. Yogyakarta : ANDI. 